\title{
Primeiras abordagens sobre o Sítio Arqueológico-Paleontológico Araçá, Município de Corrente, Extremo Sul do Piauí
}

\author{
Keyla Maria Ribeiro Frazão* \\ Juan Carlos Cisneros** \\ Abrahão Sanderson Nunes Fernandes da Silva***
}

FRAZÃO, K.M.R.; CISNEROS, J.C.; SILVA, A.S.N.F. Primeiras abordagens sobre o Sítio Arqueológico-Paleontológico Araçá, Município de Corrente, Extremo Sul do Piauí. R. Museu Arq. Etn., 30: 84-103, 2018.

Resumo: Este artigo tem como objetivo fornecer análises preliminares e sugerir a elaboração de um modelo preditivo para a arqueologia no extremo sul do estado do Piauí, levando em consideração as características geoambientais da região e um sítio paleontológico e arqueológico no município de Corrente, Piauí. A área de estudo apresenta arenito silicificado e abundantes artefatos líticos, produzidos essencialmente a partir dessa matéria-prima, além de restos fósseis de Eremotherium laurillardi, uma espécie de mamífero típica do Pleistoceno final americano. Acredita-se que a presença de instrumentos líticos esteja ligada à disponibilidade da matéria-prima, portanto, um modelo preditivo considerando esse padrão prevê a probabilidade de recursos arqueológicos em outras áreas que expõem camadas sedimentares com arenito silicificado. Embora tenha sido observada a presença de artefatos líticos na área dos fósseis, análises estratigráficas e paleoambientais detalhadas do afloramento, bem como a datação das evidências, serão necessárias para melhor entender a relação entre o ser humano e a megafauna nesse local.

Palavras-chave: Geologia; Instrumentos líticos; Megafauna; Transição Pleistoceno-Holoceno; Amostragem regional.

\section{Introdução}

estado do Piauí é conhecido
internacionalmente por abrigar uma diversidade de sítios arqueológicos. Isso deve-se,

\footnotetext{
*Arqueóloga, Núcleo de Arqueologia do Instituto de Pesquisas Científicas e Tecnológicas do Estado do Amapá. <keyla-frazao@hotmail.com>

**Docente do Departamento de Arqueologia, Universidade Federal do Piauí.<juan.cisneros@ufpi.edu.br>

***Docente do Departamento de História, Centro de Ensino da Região Seridó, Universidade Federal do Rio Grande do Norte. <abrahaosanderson@hotmail.com>
}

essencialmente, às pesquisas desenvolvidas na região da Serra da Capivara, sul do estado, desde a década de 1970, coordenadas por Niéde Guidon (Prous \& Ribeiro 2010). Entretanto, embora tenha-se conhecimento da existência de registros arqueológicos em diversas regiões, os estudos estão concentrados na região correspondente ao Parque Nacional (Parna) da Serra da Capivara e seu entorno, em consequência da falta de conhecimento e incentivo financeiro nas demais áreas. Em outras regiões do Piauí, ocorrem pesquisas esporádicas de origem acadêmica, ou por 
intermédio da arqueologia de salvamento, esta última resultante, basicamente, do crescimento de empreendimentos como obras de infraestrutura.

As pesquisas realizadas no Parna da Serra da Capivara evidenciaram ao longo dos anos uma rica fauna pleistocênica, muitas vezes associada a instrumentos líticos. Essas investigações, no entanto, priorizam o estudo de abrigos areníticos com pinturas rupestres (Felice 2006). Conforme a autora, a diversidade de sítios arqueológicos e paleontológicos na região está estreitamente vinculada a fatores geográficos e ambientais, tais como localização privilegiada e disponibilidade de recursos, decorrentes do esboço geológico e geomorfológico da área em questão.

A arqueologia, "is a truly multi-disciplinary, and that it defies all attempts to pigeon-hole it either as a science or as one of the humanities" (Greene 2003: 130) e, nesse sentido, tem nos seus métodos e material de estudo uma forte ligação com a geologia e geografia. Para autores como Araujo (1999) e Binford (2001), o nascimento da disciplina arqueológica está estreitamente vinculado a problemas geológicos, como a associação de vestígios, estratigrafia e cronologia. Não se pode deixar de mencionar também as relações humanas com a natureza, evidenciadas por meio de registros e/ou marcas na paisagem.

Em outras palavras, a arqueologia pode ser também caracterizada como "the study of the past through material remains. It is about three things: objects, landscapes and what we make of them" (Gamble 2008: 2). Nesse contexto, podese afirmar que a distribuição dos recursos arqueológicos no espaço é padronizada, entre outros fatores, pelo comportamento das populações pretéritas, aliado às suas ações na paisagem e aos processos naturais (Kipnis 1997). Segundo Kipnis (1997), a existência de tendências entre as localizações de sítios arqueológicos permite o desenvolvimento de modelos preditivos, tomando como base uma ou mais variáveis distribuídas regionalmente. Tal perspectiva está presente na arqueologia a partir de diversos autores (Jochim 1976; Pilgram 1987;
Warren 1990), e conceitualmente pode ser definida como "a simplified set of testable hypotheses, based either on behavioural assumptions or on empirical correlations, which at a minimum attempts to predict loci of past human activities resulting in the deposition of artifacts or alteration of the landscape" (Kohler 1988: 33).

Um modelo preditivo, neste caso em específico, pode ser compreendido como previsões sobre um determinado fenômeno arqueológico considerando os dados secundários disponíveis (por exemplo, imagens satélites, esboço geológico, geomorfológico, recursos hídricos) para a região de estudo, bem como as características de uma parcela e/ou amostra dela, observadas por meio de atividades de campo. Desse modo, ao descobrir a existência de um padrão, o pesquisador poderá desenvolver hipóteses que justifiquem o padrão observado. Assim, a presença de características geoambientais similares ao longo de determinada região poderá fornecer subsídios relevantes para sua caracterização com base em uma amostra dela advinda. Partindo desse princípio, será proposto um modelo que, ao incorporar tanto a perspectiva teórica quanto a empírica, poderá fornecer uma estratégia de investigação mais eficiente.

Este artigo tem como premissa caracterizar geoambientalmente a área de estudo e verificar a possível relação entre a presença de megafauna (Megatheriidae: Eremotherium laurillardi) e os abundantes artefatos culturais observados em um novo sítio no município de Corrente/PI. Pretende-se, ainda, sugerir a elaboração de um modelo preditivo para o extremo sul piauiense, baseado nas ocorrências de arenitos silicificados e materiais arqueológicos elaborados a partir dessa matériaprima na região.

Tendo em vista a disponibilidade de matériaprima no ambiente em foco e o conhecimento prévio das variáveis geoambientais do extremo sul do Piauí, evidenciadas a partir de imagens satélites e do mapa geológico do estado (CPRM 2006), acredita-se na potencialidade arqueológica da região. $\mathrm{O}$ fator principal que permitiria tal 
inferência consiste na presença de características geológicas similares ao longo dessa área. Um aspecto que chamou a atenção nesse sítio foi a ocorrência de materiais paleontológicos e arqueológicos dispostos na mesma área. Devido a isso, foram realizadas análises estratigráficas preliminares buscando entender a relação entre os fósseis e os instrumentos culturais, assim como identificar os processos geológicos envolvidos na formação da estratigrafia local.

\section{Material e métodos}

Este trabalho foi desenvolvido a partir de perspectivas ligadas à geoarqueologia e valendose ainda de elementos interpretativos da paisagem, com o propósito de compreender a relação ser humano/natureza no espaço. Dessa forma, a pesquisa foi realizada em três etapas: a primeira consistiu em uma determinação preliminar das áreas de interesse do projeto, definidas através de aspectos geológicos, observados por meio de imagens de satélites do programa Google Earth e do Mapa geológico do Piaui (CPRM 2006). Tal ação levou em consideração as ocorrências arqueológicas e geológicas observadas em campo no primeiro semestre do ano de 2013, durante campanha de escavação paleontológica no Sítio Araçá, município de Corrente. A metodologia empregada incide no desenvolvimento de modelos preditivos regionais que procuram prever ocorrências de sítios arqueológicos, em determinadas áreas, com base em padrões observados numa amostra dessa região (Araujo 2001; Kipnis 1997).

A segunda etapa compreendeu a busca por materiais bibliográficos, tomando-se por base o que já foi publicado em relação às seguintes temáticas: aspectos geoambientais da área de estudo, o uso de modelos preditivos em arqueologia, e a ocorrência de artefatos arqueológicos associados a fósseis pleistocênicos. A literatura permitiu verificar os vínculos existentes entre os fatores geoambientais e a ocupação de um determinado espaço, bem como a sua aplicação na detecção de sítios e/ou ocorrências arqueológicas, e ainda, casos de sítios semelhantes que registraram artefatos líticos associados à megafauna, fisicamente e comportamentalmente, e as discussões em torno do assunto.

A terceira etapa foi realizada em campo. No primeiro momento, foi feita uma análise visual do espaço, observando a morfologia do local, a distribuição espacial dos materiais de estudo, os elementos fisiográficos, a topografia do terreno e as condições de visibilidade (Criado Boado 1999). No segundo momento, a adoção de métodos geoarqueológicos permitiu examinar preliminarmente a estratigrafia do sítio a partir do afloramento exposto, sendo possivel analisar as camadas de deposição e seus elementos constituintes como, por exemplo, os tipos de solos e as variações quanto às tonalidades (Bitencourt 2008; Rapp $\&$ Hill 2006). Na ocasião, foi elaborado um perfil geológico do afloramento, sem mapear as diferenças horizontais ao longo da área, e buscando situar no contexto estratigráfico as ocorrências observadas.

Durante as atividades de campo, foi feito o registro das características geoambientais e ocorrências paleontológicas e arqueológicas, com câmera fotográfica digital e mapeamento georreferenciado, utilizando um receptor de sistema de posicionamento global de navegação. Os artefatos arqueológicos encontrados não foram coletados, apenas documentados in loco.

\section{Caracterização geoambiental do extremo sul do Piauí}

\section{Área de abrangência}

A área de abrangência do trabalho compreende a microrregião de Chapadas do Extremo Sul Piauiense, englobando os seguintes municípios: Morro Cabeça no Tempo, Curimatá, Riacho Frio, Avelino Lopes, Júlio Borges, Sebastião Barros, Parnaguá, Cristalândia do Piauí e Corrente (Fig. 1). O município de Corrente distinguese dos demais por abrigar o sítio arqueopaleontológico Araçá, abordado neste trabalho. 


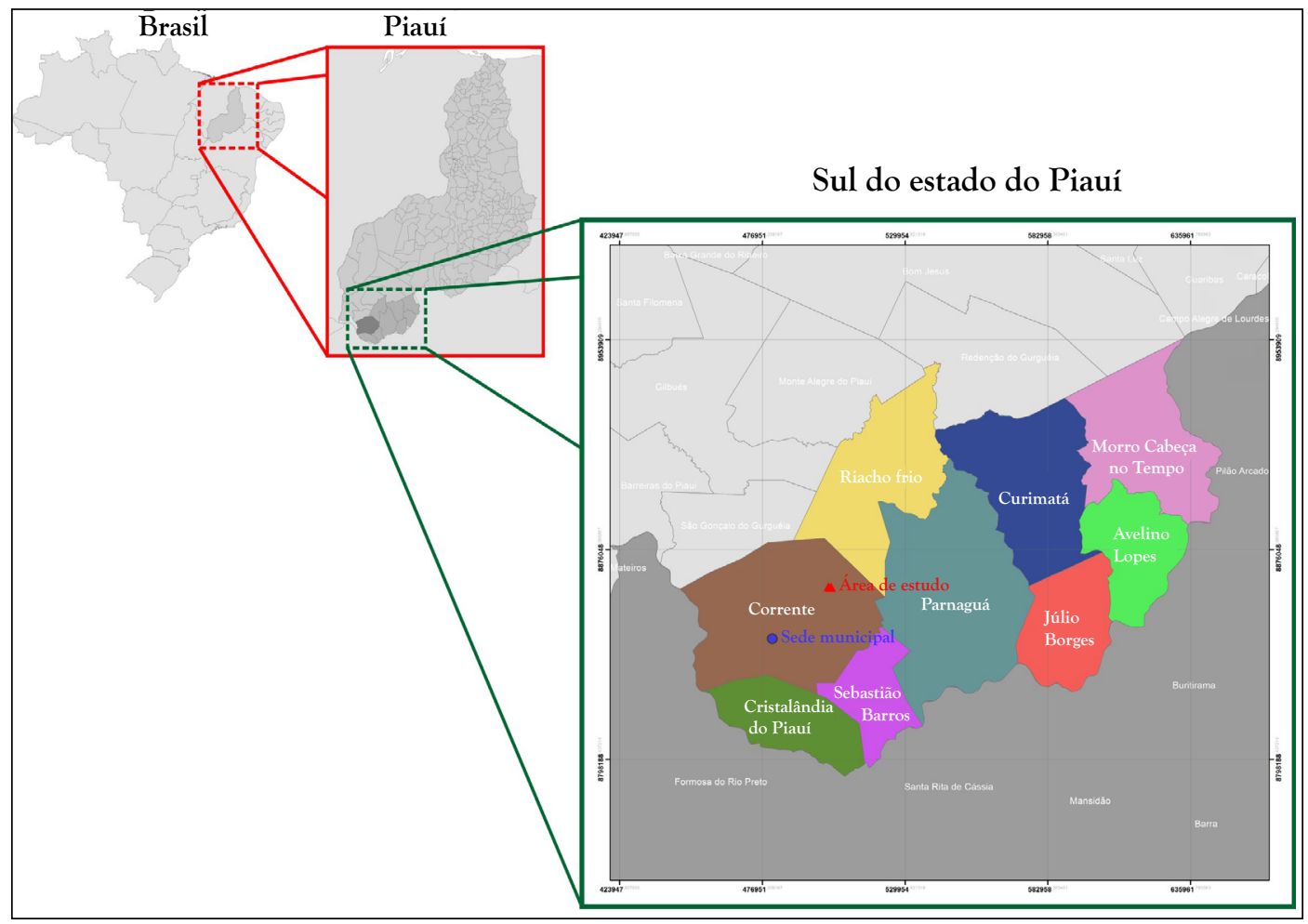

Fig. 1. Localização do extremo sul do Piauí e da área do sítio arqueopaleontológico Araçá, destacada em vermelho. Fonte: Frazão (2015).

\section{Geologia}

O extremo sul do Piauí (Fig. 2) compreende a província geotectônica de Borborema e coberturas sedimentares das bacias do Parnaíba e do São Francisco (Aguiar \& Gomes 2004a, b, c, d, e, f, g, h, i; CPRM 2006).

O substrato da província Borborema caracteriza-se por apresentar feições geológicas antigas retrabalhadas, novas feições e unidades geológicas, decorrentes do aumento da atividade tectônica no ciclo Brasiliano (Mabessone 2002). A litoestratigrafia da área de estudo exibe terrenos antigos, formados por rochas do embasamento cristalino, denominada Complexo Cristalândia do Piauí, de idade neoarqueana (Lima \& Brandão 2010). As litologias são compostas especialmente por muscovita, biotita, ortognaisses graníticos, ortognaisses e paragnaisses, com níveis de rochas metamáficas, metaultramáficas e calcissilicáticas (Aguiar \& Gomes 2004a, b, c, d, e, f, g, h, i; CPRM 2006).

A Bacia Sedimentar do Parnaíba, essencialmente paleozoica, ocupa cerca de $80 \%$ do território piauiense e está representada na região em foco pelo Grupo Serra Grande, composto de conglomerado, arenito, intercalações de siltito e folhelho, e pelo Grupo Canindé, representado pelas formações: Pimenteiras, englobando arenito, siltito e folhelho; Longá, composta por arenito, siltito, folhelho e calcário; Cabeças, formada por arenito, conglomerado e siltito; e Poti, com arenito, folhelho e siltito (Aguiar \& Gomes 2004a, b, c, d, e, f, g, h, i; Lima \& Brandão 2010; Santos \& Carvalho 2004). As formações supracitadas pertencem ao período Devoniano, com exceção da Formação Poti, de idade carbonífera (CPRM 2006). 


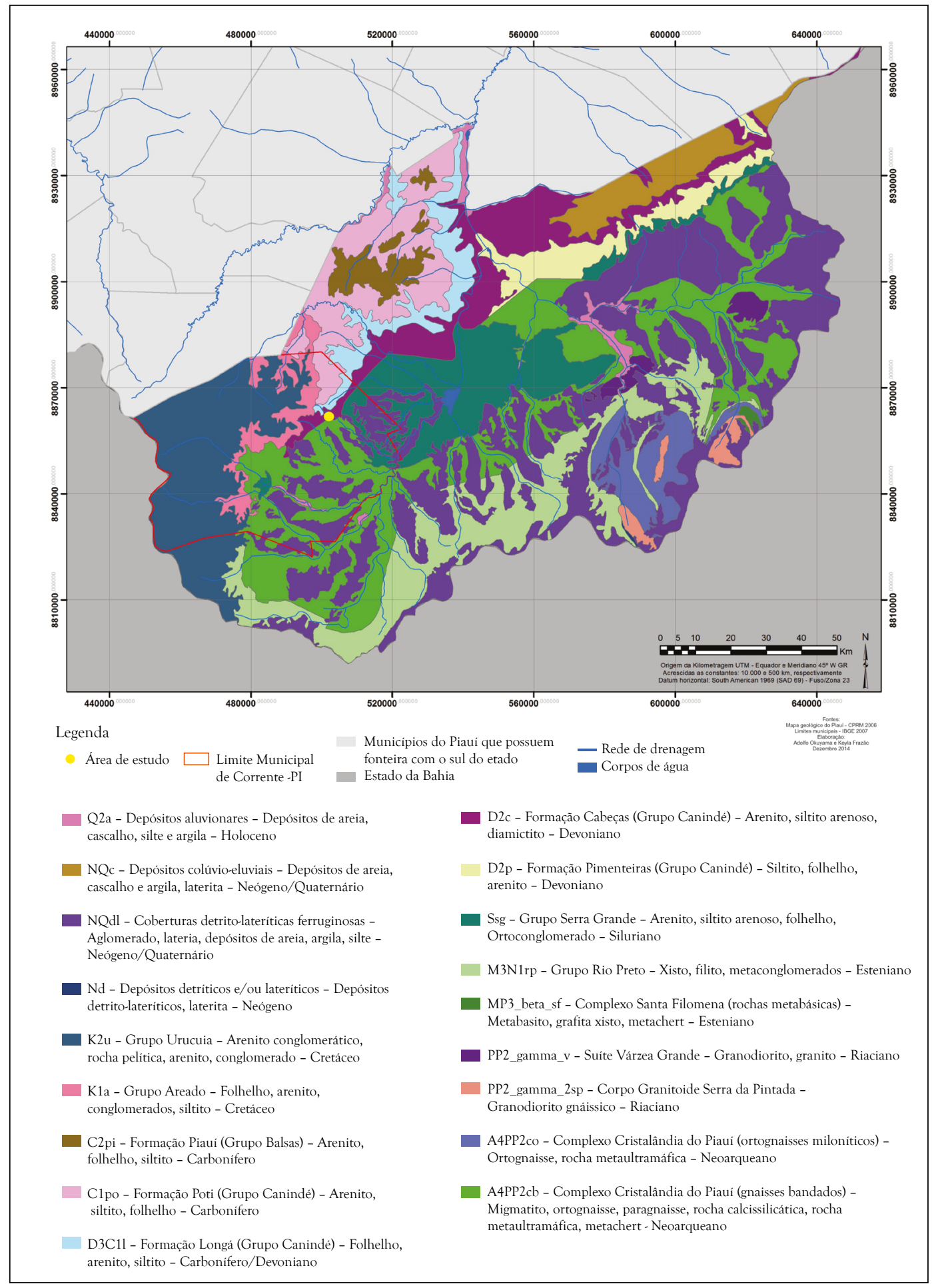

Fig. 2. Esboço geológico do extremo sul do estado do Piauí.

Fonte: Frazão (2015). 


\begin{abstract}
A Bacia Sanfranciscana representa a cobertura sedimentar fanerozoica do Cráton do São Francisco e unidades de embasamento (Campos \& Dardenne 1997). O esboço geológico dos municípios contemplados pela pesquisa apresenta, sobretudo, as seguintes unidades: Formação Areado (Eocretáceo), englobando arenito, conglomerado e folhelho; e Formação Urucuia (Neocretáceo), composta por arenito e conglomerado (Aguiar \& Gomes 2004a, b, c, d, e, f, g, h, i; CPRM 2006).
\end{abstract}

As coberturas sedimentares recentes estão representadas pelos depósitos detritolateríticos (Neógeno-quaternários), envolvendo areias com níveis de argilitos, cascalho e crosta laterítica; depósitos colúvioeluviais (Neógenoquaternários), formados por sedimentos arenosos, argilosos e conglomeráticos; e depósitos aluvionares (Quaternário), representados por areia, cascalho e níveis de argila (CPRM 2006). Em relação ao embasamento cristalino, é constituído pelo Grupo Formosa do Rio Preto, englobando filito, quartzito, xisto e metaconglomerado, e através do Complexo Formosa do Rio Preto, com presença de gnaisses e rochas cataclásticas. Ocorrem ainda granitos, representando a unidade mais jovem do embasamento na área (Aguiar \& Gomes 2004a, b, c, d, e, f, g, h, i; CPRM 2006).

\section{Geomorfologia}

O relevo da região está esculpido principalmente em rochas do embasamento cristalino, datadas do Pré-Cambriano, representado pelas depressões periféricas (Lima 1987). Contudo, conforme a classificação proposta por essa autora, constata-se, ainda, ocorrências de feições geomorfológicas características dos Chapadões do Alto-Médio Parnaíba, assentadas em litologias da Bacia Sedimentar do Parnaíba.

As depressões periféricas abrangem um diversificado conjunto de padrões de relevo, compostos por inselbergs (morros residuais cristalinos realçados pela erosão diferencial com saliências onduladas), vales encaixados e pedimentos (Lima 1987). Os vales encaixados apresentam morfologias acidentadas, além de exibir evidências de rios mais ativos no passado, com vertentes retilíneas e côncavas, algumas altamente declivosas (Ferreira \& Dantas 2010; Lima 1987). Os pedimentos estão presentes especialmente no contato do rebordo da bacia do Parnaíba com as depressões periféricas.

Vale ressaltar, ainda, a presença de extensas coberturas de depósitos detrito-lateríticos neógeno-quaternários com abundantes ocorrências de arenitos silicificados, as quais geram formas similares a tabuleiros (Ferreira \& Dantas 2010). Para Lima (1987), esses registros comprovam as variações climáticas ocorridas durante o Quaternário. No tocante à topografia, verificamse altitudes com variações entre $300 \mathrm{~m}$ e $500 \mathrm{~m}$, podendo chegar a elevações maiores em algumas áreas (Ferreira \& Dantas 2010; Lima 1987).

Os Chapadões do Alto-Médio Parnaíba envolvem extensos planaltos, conhecidos regionalmente por serras, com cotas que variam entre $200 \mathrm{~m}$ e $700 \mathrm{~m}$ (Lima 1987).

De acordo com essa literatura, observam-se as seguintes feições geomorfológicas: superfícies de cimeira de planaltos conservados, morros testemunhos e vales pedimentares. A primeira consiste em áreas de cumeadas tabulares e rebordos estruturais no contato com os vales, já a segunda registra o recuo das encostas por processos pedimentares, e a última caracterizase por exibir vertentes retilíneas, com destaque para os cânions ou boqueirões formados por meio de processos tectônicos e erosivos ocorridos em épocas geológicas pretéritas nos rios Paraim e Piauí.

\section{Vegetação}

O estado do Piauí apresenta diferentes coberturas vegetais, em decorrência da influência dos domínios da Amazônia, do Planalto Central e do Nordeste, proporcionando, assim, uma diversidade de ecossistemas. $\mathrm{O}$ extremo sul piauiense apresenta flora característica do cerrado com algumas intrusões de caatinga. 
De acordo com Castro (2007), o cerrado ocupa aproximadamente $46 \%$ do território piauiense e caracteriza-se por vegetação do tipo mesófila e subcaducifólia, compostas por duas floras: arbóreo-arbustiva (lenhosa) e herbáceosubarbustiva (rasteira). Nas áreas de transição cerrado/caatinga predominam as características típicas do caducifólio.

A caatinga estendese por quase todos os estados nordestinos e algumas áreas do norte de Minas Gerais. No Piauí, é notável sua presença, principalmente no sudeste do estado, onde está assentada em áreas de depressões interplanálticas, com predominância de clima semiárido (Castro 2007). A fisionomia da vegetação apresenta-se de três tipos: caatinga arbórea, composta por galhos baixos, fechada a aberta; caatinga arbustiva, aberta e com tamanho variando entre $2 \mathrm{~m}$ e $5 \mathrm{~m}$ de altura; e por fim, caatinga arbóreo-arbustiva, apresentando estrato arbustivo fechado com árvores baixas espalhadas sobre a camada arbustiva ou com características típicas da caatinga arbustiva aberta (Castro 2007).

\section{Clima}

O estado do Piauí, de maneira geral, exibe tipologias climáticas diversificadas nas suas regiões, devido a sua inserção em áreas de transição entre o Nordeste semiárido, a Amazônia úmida e o cerrado brasileiro (Andrade Jr. et al. 2004b). De acordo com o Instituo Brasileiro de Geografia e Estatística (IBGE 2002), no extremo sul piauiense há predominância do clima tropical semiárido quente, com ocorrência de período seco por cerca de seis meses, porém, alguns municípios também apresentam características típicas do clima tropical semiúmido quente, com período seco por cerca de cinco meses.

Segundo Andrade Jr. et al. (2004a), as temperaturas no extremo sul são elevadas, apresentando média anual mínima de $16^{\circ} \mathrm{C}$ a $20^{\circ} \mathrm{C}$ e máxima de $30^{\circ} \mathrm{C}$ a $34^{\circ} \mathrm{C}$. No que concerne à umidade relativa do ar, a média anual equivale a $65 \%$. Quanto às precipitações pluviométricas, registra-se regime chuvoso de novembro a março, com índices pluviométricos entre 800 mm e 1.200 mm (Andrade Jr. 2004a).

Solos

Os solos predominantes na região são compostos principalmente pela variação entre latossolos amarelos (textura média), álicos ou distróficos, associados com areias quartzosas e/ ou podzólico vermelhoamarelo concrecionário, plíntico ou não plíntico, fase cerrado tropical subcaducifólio dominante, conhecido localmente por mata de cocais (Aguiar \& Gomes 2004a, b, c, d, e, f, g, h, i; Jacomine et al. 1986). A pedologia local possui idade jovem e deriva especialmente da alteração das seguintes litologias: arenitos, granitos, gnaisse, folhelhos, filito, siltitos, argilito, xisto, conglomerado, quartzito, laterito, metaconglomerado, metarenito, metassiltito, granodiorito, tonalito e rochas cataclásticas (Aguiar \& Gomes 2004a, b, c, d, e, f, g, h, i; Jacomine et al. 1986).

\section{Recursos hídricos superficiais}

A região é drenada pela bacia do rio Gurgueia, um dos principais afluentes da bacia hidrográfica do rio Parnaíba, que envolve aproximadamente $75,3 \%$ do estado piauiense, estendendo-se pelos estados do Maranhão, Ceará e zona de litígio, ocupando uma área total de $331.441 \mathrm{~km}^{2}$ (MMA 2006). Conforme o Ministério do Meio Ambiente (MMA 2006), a subbacia do Gurgueia está situada no Alto Parnaíba, essencialmente no bioma Cerrado, com algumas ocorrências em áreas de caatinga. Além do mais, apresenta um potencial hidrológico subterrâneo diferenciado das demais regiões do estado.

$\mathrm{O}$ rio Gurgueia nasce no município de Barreiras do Piauí, na Chapada das Mangabeiras, e apresenta caráter perene na maioria dos seus trechos. Em conjunto com seus afluentes, com ênfase para os rios Paraim, Curimatá, Corrente e os riachos da Tábua e de Santana, dá origem à denominada bacia do Gurgueia, com 48.839 km² de extensão, 
responsável por drenar todo o extremo sul do estado (MMA 2006). Cabe ressaltar, ainda, que a área apresenta uma quantidade considerável de açudes e lagoas de notável expressão, como a lagoa de Parnaguá.

\section{Descrição do sítio}

Durante a etapa de prospecção superficial, observou-se no espaço a existência de três pontos de concentração dos materiais que são objeto deste artigo, os quais apresentam entre si algumas diferenças no que concerne aos aspectos geoambientais e culturais. Dessa maneira, visando a uma melhor caracterização do ambiente, optou-se por dividi-lo em três áreas, conforme será demonstrado adiante.

O ambiente de estudo, com exceção da Área 3, está situado numa extensa voçoroca (Fig. 3), formada por processos erosivos que ocasionaram a exposição de estratos, nos quais é possível verificar as camadas de deposição e, consequentemente, sua constituição. No local, observa-se a ocorrência de coberturas detritolateríticas neógenoquaternárias (Província Parnaíba), compostas por arenitos com níveis de argilitos, cascalhos e crosta laterítica, predominantes no extremo sul do Estado (CPRM, 2006).

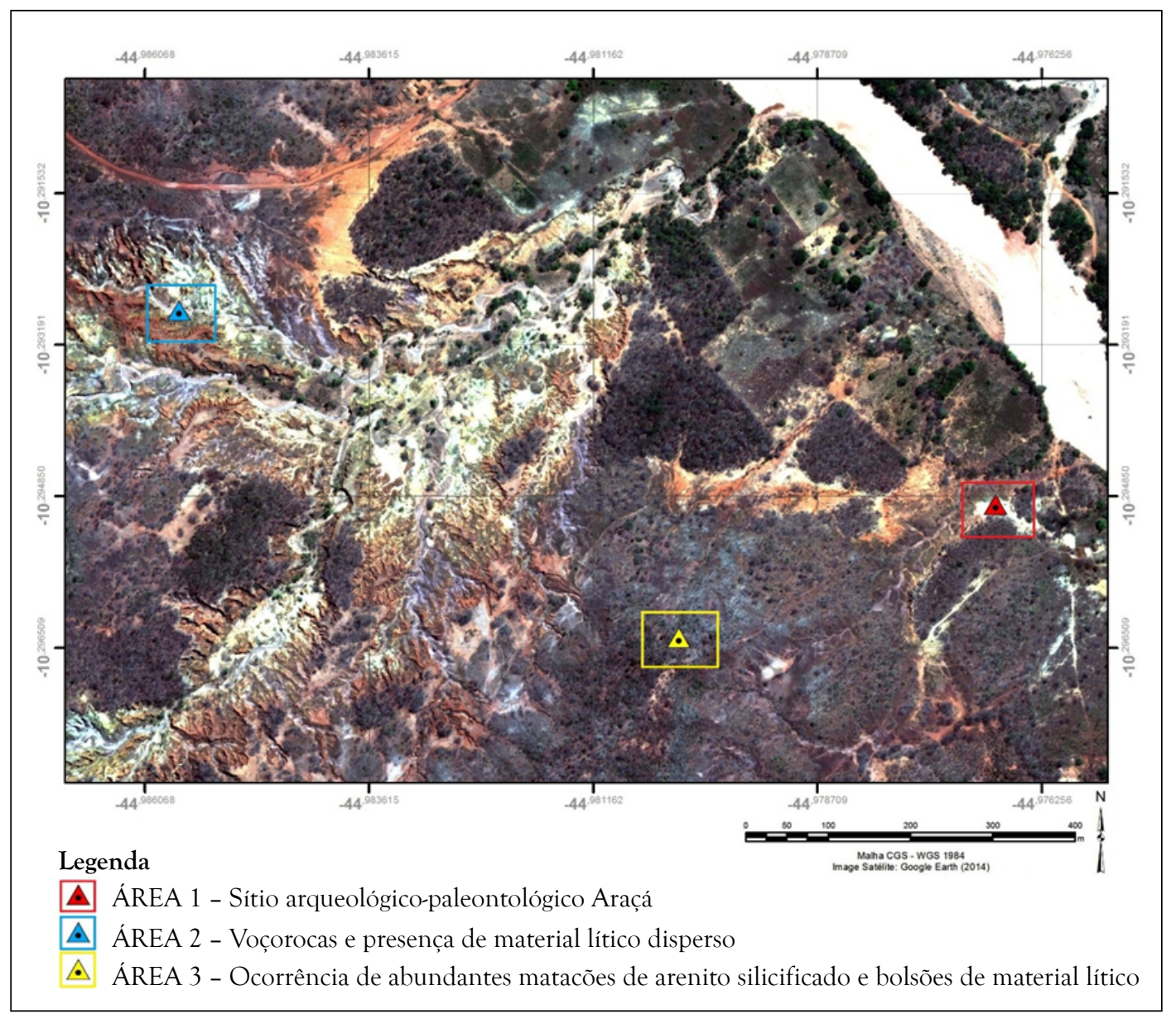

Fig. 3. Imagem de satélite evidenciando as três áreas abordadas no trabalho. Notase que a Área 1 (Sítio arqueológico-paleontológico Araçá) está situada às margens do Rio Grande, o que intensificou os processos erosivos nesse ambiente.

Fonte: Frazão (2015). 
Primeiras abordagens sobre o Sítio Arqueológico-Paleontológico Araçá, Município de Corrente, Extremo Sul do Piauí R. Museu Arq. Etn., 30: 84-103, 2018.

Área 1

Essa área encontrase marcada por contínuas intervenções humanas, resultantes da retirada de argila na década de 1990 para confecção rudimentar de telhas e tijolos, além de desgastes erosivos provocados pela ação da água da chuva e da drenagem do Rio Grande, situado às margens do afloramento (Fig. 4A). A retirada de argila provocou a descoberta, em 2011, de um sítio paleontológico que contém megafauna pleistocênica (Fig. 4B). Desde o ano de 2013, campanhas de escavação vêm sendo realizadas no local com o intuito de recuperar os elementos ósseos do animal, que podem ajudar a entender como era o paleoambiente naquela época, além de esclarecer a relação entre o ser humano e a megafauna nesse sítio.

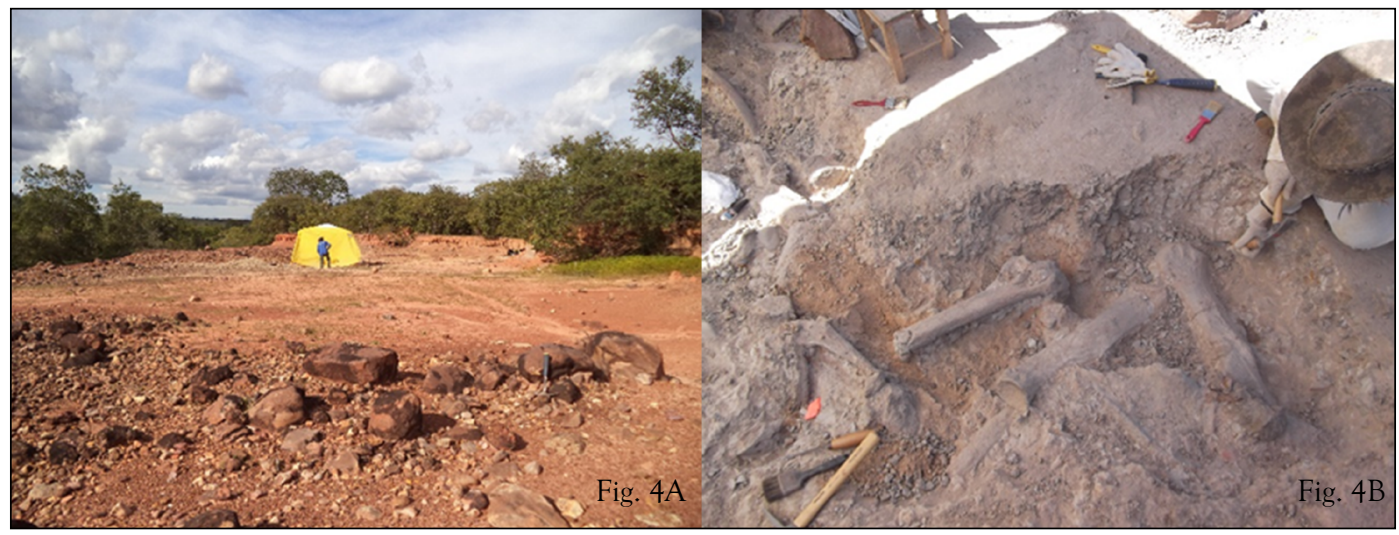

Fig. 4A. Vista geral do depósito de argila que alberga os fósseis de Eremotherium e instrumentos líticos.

Fig. 4B. Elementos ósseos de Eremotherium laurillardi evidenciados na Área 1.

Fonte: acervo dos autores.

Na superfície, há ocorrências de matacões de arenito silicificado e artefatos líticos lascados elaborados a partir dessa matéria-prima, em grandes quantidades. Verificam-se também alguns registros de vestígios arqueológicos em arenito, quartzito e ocre. Contudo, os outros materiais encontrados são seixos e pequenos blocos de arenito e quartzito, sendo ausente o ocre na área de estudo.

$\mathrm{O}$ arenito silicificado, uma das principais matérias-primas utilizadas pelas populações pré-coloniais para a elaboração de instrumentos líticos lascados, nesse ambiente, apresenta-se mais silicificado, o que implica numa melhor qualidade para o lascamento, facilitando sua utilização na fabricação dos instrumentos. No tocante aos materiais arqueológicos, observou-se diferenças do ponto de vista tecnológico entre os artefatos encontrados no afloramento às margens do rio e aqueles observados ao longo da superfície do terraço fluvial que abriga os fósseis. $O$ primeiro exibe instrumentos líticos mais simples, como lascas (com retoque e sem retoque) e núcleos (Fig. 5A), e instrumentos unifaciais (Fig. 5B), enquanto o segundo expõe utensílios mais elaborados (Figs. 5C e 5D) como, por exemplo, pontas bifaciais, plano-convexos e lascas bem retocadas.

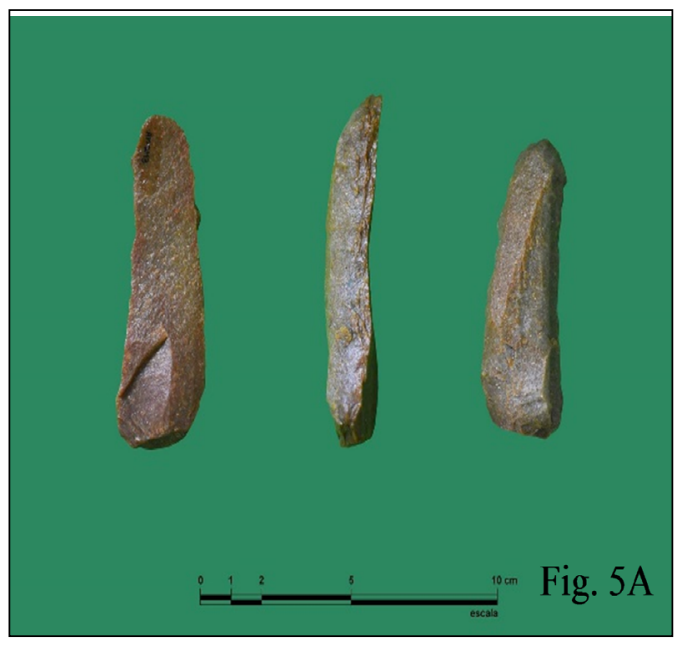



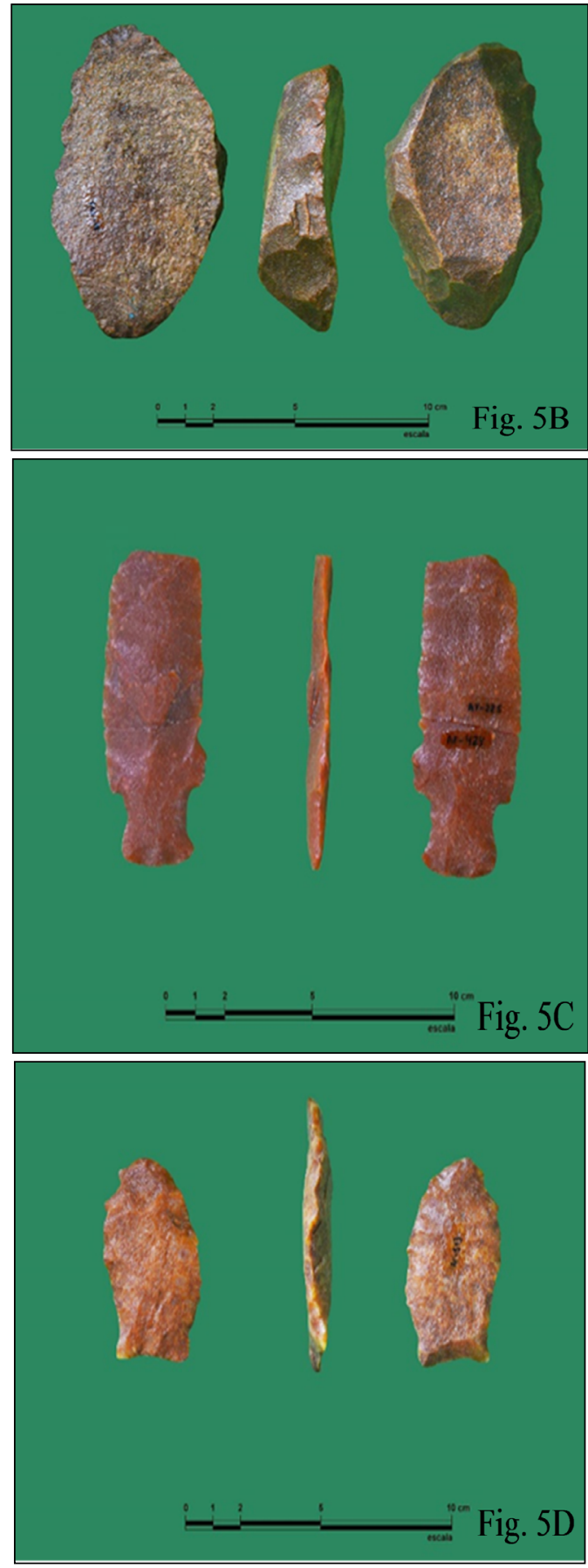

Fig. 5A. Lasca com retiradas no bordo direito.

Fig. 5B. Instrumento unifacial sobre lasca.

Fig. 5C. Ponta bifacial.

Fig. 5D. Ponta bifacial.

Fonte: acervo dos autores.
O pacote sedimentar (Fig. 6) que contém os fósseis pode ser correspondente a uma antiga planície de inundação, formada pela decantação de sedimentos finos. A distribuição espacial dos ossos no depósito quando das atividades de escavação paleontológica não demonstra a ocorrência de grandes deslocamentos, estando as estruturas ósseas de grande, médio e pequeno porte associadas. A movimentação horizontal por agentes naturais de transporte poderia ocasionar a separação dos ossos maiores dos menores, uma vez que o material mais leve exige menos energia para ser transportado. Nesse pacote, ocorrem variações laterais na tonalidade, a qual é predominantemente laranja-tijolo, apresentando, contudo, uma coloração cinza clara na área dos fósseis. Vale mencionar ainda, a existência de abundantes artefatos líticos rolados em todos os estratos, a grande maioria, confeccionados em arenito silicificado. Essas características estão representadas no perfil geológico a seguir, acompanhado da descrição das camadas, conforme os princípios temporais da estratigrafia, sendo, da base para o topo:

1. ocorrência de siltito na coloração arroxeada, contendo mica, além de icnofósseis de invertebrados. Esta camada é visível nas margens do Rio Grande; 2. constituída por argilito na coloração cinza clara com aspecto esverdeado, contendo mica;

3. composta por siltito, o qual se gradua da base para o topo nas colorações terracota, amarelo escuro e roxo, contendo mica e óxido de ferro;

4. em virtude da presença de cobertura vegetal não foi possível verificar sua constituição;

5. representada por folhelhos (siltito) de coloração cinza, roxo e terracota, com bandas avermelhadas no topo;

6. compreende arenito fino na coloração roxa com intercalações avermelhadas; 7. envolve argilito tendendo ao siltito, na coloração cinza clara, contendo óxido de ferro;

8. folhelhos compostos por silte, o qual se gradua da base para o topo nas cores de cinza médio a cinza claro; 
Primeiras abordagens sobre o Sítio Arqueológico-Paleontológico Araçá, Município de Corrente, Extremo Sul do Piauí R. Museu Arq. Etn., 30: 84-103, 2018.

9. pacote sedimentar quaternário constituído por duas camadas de material argiloso, separadas por uma linha de seixo com artefatos arqueológicos in situ: (a) a primeira delas, com aproximadamente $60 \mathrm{~cm}$ de espessura, apresenta coloração laranja-tijolo variando a cinza claro na área fossilifera, onde foram encontrados os remanescentes fósseis de um Eremotherium laurillardi (UFPI-PV507), depositado no Laboratório de Paleontologia, Centro de Ciências da Natureza,

Universidade Federal do Piauí); (b) a segunda camada, de cor laranja-tijolo, contém seixos e matacões de arenito silicificado, estando associada aos artefatos líticos evidenciados em contexto estratigráfico, podendo estar relacionada também a um antigo paleocanal do Rio Grande.

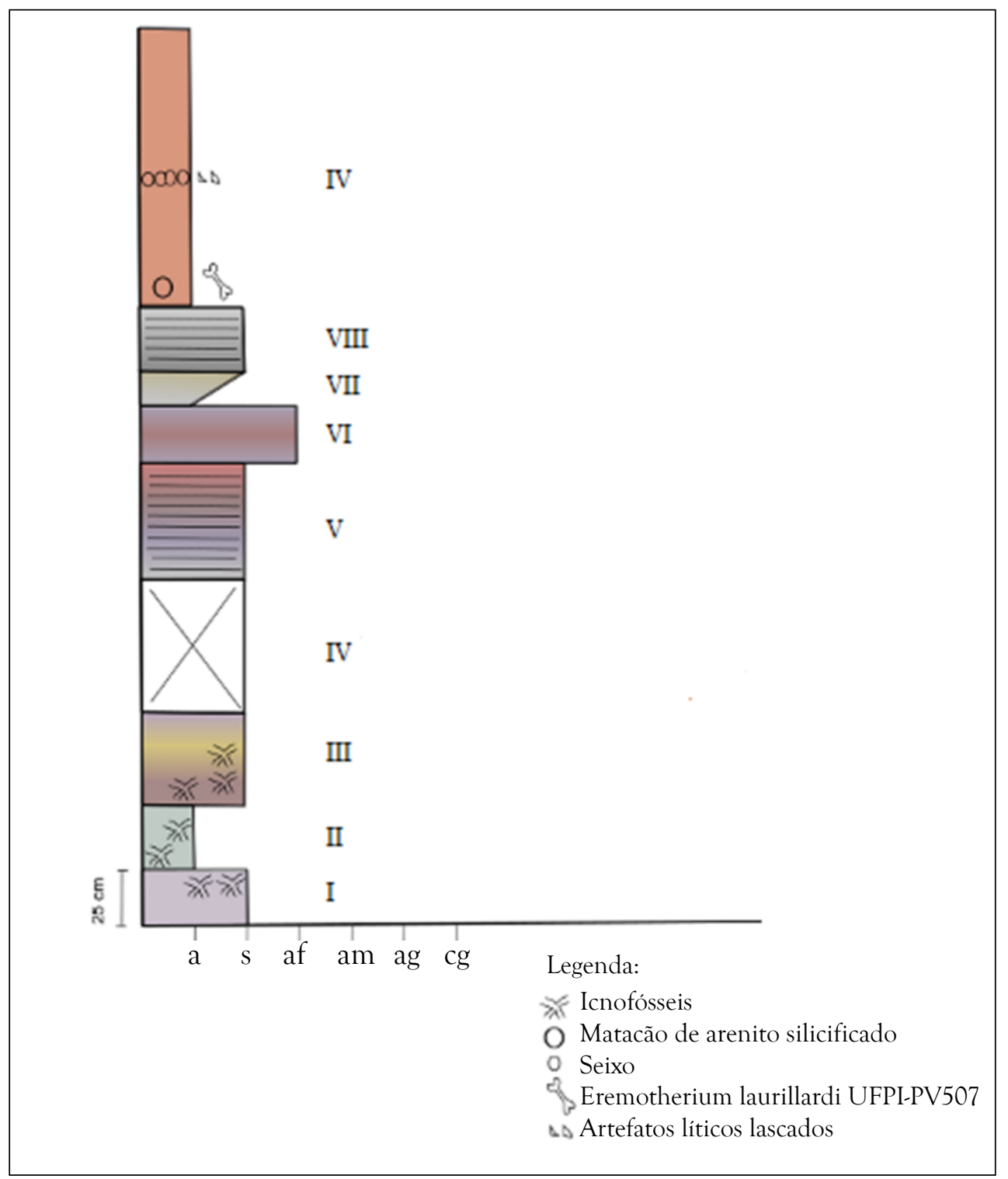

Fig. 6: Perfil geológico simplificado do sítio Araçá.

Fonte: elaboração própria. 
Área 2

Outra área com potencial arqueológico é o afloramento às margens de uma estrada vicinal que liga a localidade Porta do Araçá à rodovia que dá acesso à sede do município de Corrente (Fig. 7). Nesse local, encontram-se pontos isolados com concentração de seixos de materiais variados, que foram formados por meio de erosão pluvial, a qual deu origem a pequenos córregos. Entre os materiais que compõem essas áreas de acúmulo estão os seixos de sílex, arenito, quartzo e artefatos líticos.

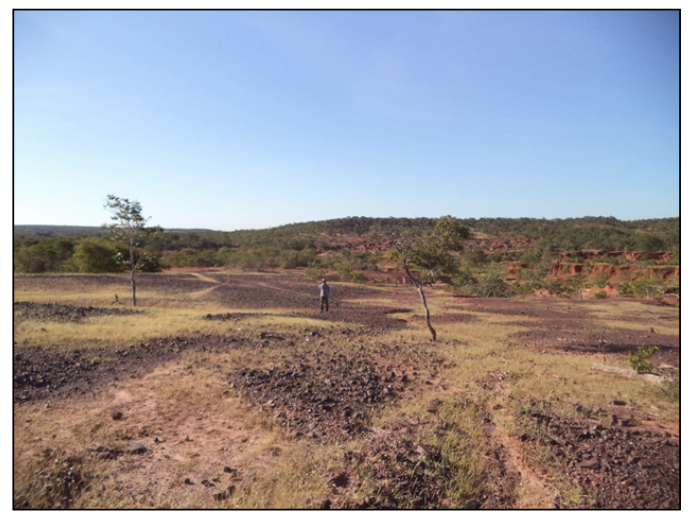

Fig. 7. Vista geral da Área 3 evidenciando uma extensa voçoroca.

Fonte: acervo dos autores.

O ambiente apresenta, ainda, matacões de arenito silicificado rolados e um bloco de sílex com marcas de lascamento. Os instrumentos culturais estão dispersos ao longo da área, sendo representados essencialmente por lascas simples, núcleos e peças unifaciais, todavia, também se observam instrumentos bifaciais (Fig. 8). Nos espaços ainda não afetados pela erosão, situados nas partes mais elevadas ao redor dessa localidade, verificam-se coberturas detrito-lateríticas constituídas por, entre outros materiais, cascalhos, pequenas couraças ferruginosas e artefatos arqueológicos. A matériaprima predominante nessa área é o arenito silicificado, embora seja também recorrente o uso do sílex e do quartzo, este último com poucas ocorrências.

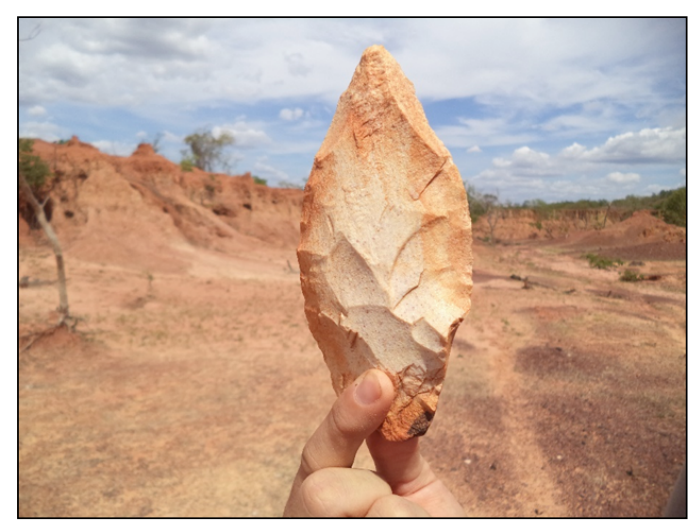

Fig. 8. Instrumento bifacial identificado em superfície. Fonte: acervo dos autores.

Área 3

Esse ambiente está situado na parte mais elevada do platô, a $488 \mathrm{~m}$ de altitude, $50 \mathrm{~m}$ acima do nível portador do espécime de Eremotherium, e encontra-se parcialmente coberto por vegetação de pequeno e médio porte. Distingue-se das demais áreas pela presença, em superfície, de afloramentos com abundantes matacões de arenitos silicificados (Fig. 9A), provavelmente associados aos grupos Areado ou Urucuia (Bacia Sanfranciscana). Há ocorrência de bolsões de lascamento contendo produtos líticos diversificados (Fig. 9B).

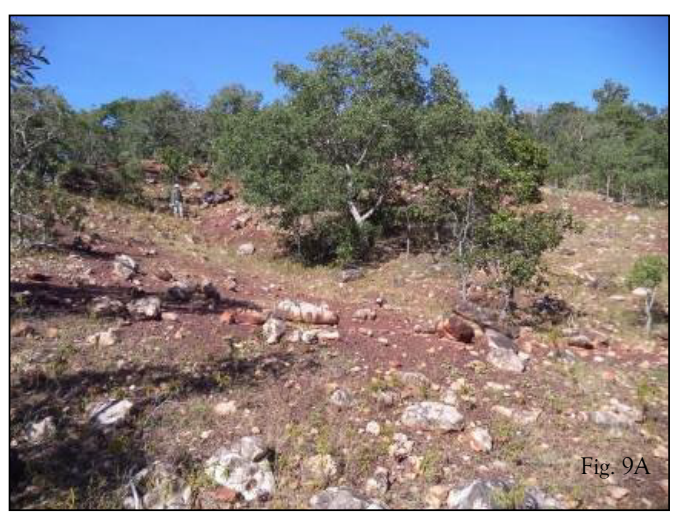




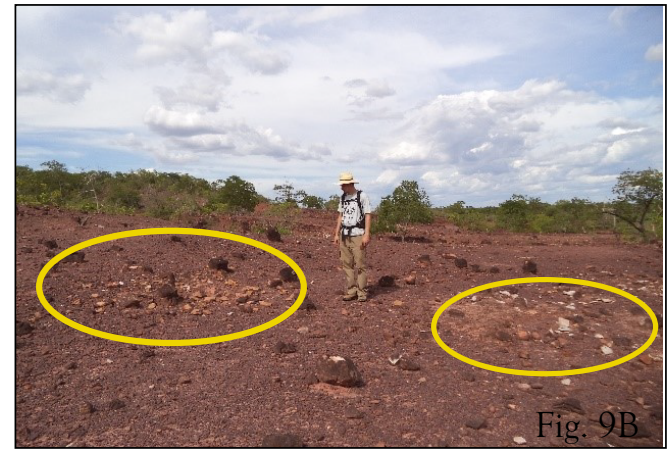

Fig. 9A. Abundantes matacões de arenito evidenciados na superfície da Área 3.

Fig. 9B. Os círculos indicam bolsões de lascamento observados na Área 3.

Fonte: acervo dos autores.

Esse local apresenta instrumentos líticos, predominantemente produzidos pelo uso do arenito como matéria-prima, e alguns utensílios confeccionados a partir do sílex e quartzo. Além do mais, os suportes de sílex e quartzitos verificados não parecem ser favoráveis ao lascamento. Os artefatos arqueológicos possuem características tecnológicas semelhantes àquelas verificadas no afloramento às margens do Rio Grande (Área 1) e na Área 2, o que indica a possibilidade de tratar-se de um mesmo sítio. Nota-se que o local é alvo de intemperismo pluvial, no entanto, devido à presença de cobertura vegetal, esse agente atua com menor intensidade, ao comparar com as demais áreas.

\section{Resultados e discussão}

\section{Instrumentos líticos}

A existência de materiais líticos na área de estudo está associada, em parte, ao aproveitamento e escolha do arenito silicificado pelos artesões que habitaram a região. Isso pode estar relacionado com as propriedades físicas dessa matériaprima (por ex. arredondamento dos grãos, circularidade e granulometria) e ao processo de silicificação, trazendo implicâncias na aptidão ao lascamento (Araujo 1992). Em relação aos materiais arqueológicos confeccionados em quartzito, é possivel inferir que houve transporte humano, assim como com o ocre, uma vez que foi constatada sua ausência na estrutura geológica local (CPRM 2006).

As diferenças tecnológicas evidenciadas nos instrumentos líticos podem sugerir a presença de indústrias líticas distintas. Os utensílios mais simples podem denotar um período de ocupação mais recente, enquanto aqueles mais elaborados, ao que tudo indica, referemse a uma indústria lítica típica da transição entre o Pleistoceno e o Holoceno americano, evidenciadas em toda a região nordeste e no centro-oeste, passíveis de serem relacionados à Tradição Itaparica (Fogaça \& Lourdeau 2008; Lourdeau 2006).

O termo "Tradição Itaparica" foi utilizado pela primeira vez por Valentin Calderón na década de 1960, mediante pesquisas realizadas na Gruta do Padre, sítio arqueológico localizado no estado de Pernambuco (Fogaça \& Lourdeau 2008; Silva 2003). Calderón caracterizou essa tradição pela ocorrência de instrumentos unifaciais robustos predominantes na sequência estratigráfica do sítio em questão, os quais denominou de lesmas, em que predominam os raspadores líticos plano-convexos semicirculares, pontas-facas, pontas-raspador, lascas (sem retoque e com retoque) e buris (Fogaça $\&$ Lourdeau 2008; Marques \& Hilbert 2009; Silva 2003). Segundo Fogaça \& Lourdeau (2008), Valentin dividiu essa tradição em duas fases: uma mais antiga denominada Fase Itaparica (a partir de 8.000/7.000 AP) e outra mais recente chamada de Fase São Francisco (por volta de $2.500 \mathrm{AP}$ ).

Entretanto, pesquisas desenvolvidas por Pedro Schmitz a partir da década de 1960 no estado do Goiás, especificamente no Planalto Central, permitiram recuar a Tradição Itaparica para a transição Pleistoceno/Holoceno americano, surgindo, assim, discordâncias entre as datas estabelecidas (Schmitz 1980). Na ocasião, a tradição foi dividida em duas fases: Fase Paranaíba (datada entre 11.000 e 8.500 AP) e Fase Serranópolis (datada entre 8.500 e 6.500 AP). A primeira apresenta características tecnológicas elaboradas parecidas com aquelas verificadas por Calderón na Gruta do Padre, enquanto a segunda, ainda pouco definida, 
é composta basicamente por lascas pouco retocadas e ausência de peças padronizadas (Fogaça \& Lourdeau 2008; Lourdeau 2006).

Entretanto, considerando o caráter preliminar deste trabalho, é evidente a necessidade de análises tecnológicas dos materiais líticos, já contempladas em uma dissertação de mestrado por Oliveira (2017). De igual modo, a ausência de estudos envolvendo a perspectiva de análise do registro sedimentar do sítio, evidencia lacunas no que se refere ao processo de formação do registro arqueológico, tanto do ponto de vista sedimentar quanto pelo contexto paleoambiental local. Essas perspectivas de análise foram abordadas sob um viés geoarqueológico por Frazão (2018).

\section{Megafauna e artefatos culturais}

A presença humana na América do Sul é considerada umas das temáticas mais debatidas e polêmicas da arqueologia americana (Neves \& Piló 2008). Os principais aspectos que norteiam o debate estão relacionados à chegada dos primeiros hominídeos ao continente, podendo-se citar: a idade, o percurso traçado, a genealogia e as relações estabelecidas com o meio ambiente. Segundo Neves \& Piló (2008), a hipótese mais aceita sobre a chegada do ser humano neste continente data de aproximadamente $12 \mathrm{mil}$ anos, coincidindo com a transição Pleistoceno/Holoceno. Dessa forma, é possivel que os primeiros habitantes tenham interagido com espécies pertencentes à megafauna pleistocênica. Cabe ressaltar que pesquisas desenvolvidas na região da Serra da Capivara culminaram na datação mais antiga acerca do povoamento do continente americano, com idade estimada em 48.000 anos AP e evidências que apontam para uma ocupação ainda mais recuada (Guidon et al. 2003). Porém, as cronologias acima de $12 \mathrm{mil}$ anos estabelecidas para essa região são um tanto polêmicas no meio científico (Prous 1997).

Ainda assim, as evidências que revelam algum tipo de interação entre o ser humano e a megafauna na América do Sul são raras (Borrero 2009; Dantas 2012; Neves \& Piló 2008; Prous
1992). A atividade humana pode ser comprovada pela presença de marcas na superfície óssea de membros da megafauna, efetuadas com um instrumento lítico, todavia, é necessário ter cautela para não as confundir com feições recentes que podem ter sido realizadas no momento da coleta dos fósseis (Borrero 2009). Segundo White \& Folkens (2005), as modificações correspondem a poços de percussão, estrias, cicatrizes internas conchoidais, esmagamento e descamação, podendo variar de acordo com a estrutura óssea do animal e o objetivo do autor da marca.

Em contrapartida, pesquisas de cunho paleontológico e arqueológico têm registrado ocorrências de artefatos líticos e remanescentes da megafauna, indicando coexistência sincrônica e espacial com maior incidência (Borrero 2009). Evidências espaciais são encontradas em quase todos os países da América do Sul. No Brasil, os indícios fazem referência à maioria dos estados, contudo, nota-se maior recorrência na região Nordeste. Quanto à coexistência sincrônica, percebem-se ainda poucos casos, o que pode estar associado, em parte, à ausência de datações, visto que é difícil estabelecer uma cronologia contemporânea apenas com base no contexto estratigráfico.

No Uruguai foi documentado um dos prováveis indícios de interações comportamentais mais antigos da América do Sul em Arroyo del Vizcaíno, estado de Canelones (Fariña et al. 2013). O registro compreende sinais de descarne no osso da pélvis de um Lestodon armatus (preguiçagigante), com datação entre 27 e 30 mil anos, além da ocorrência de artefatos líticos no ambiente, o que permitiria inferir que a ocupação humana no continente é mais antiga do que a maioria dos pesquisadores acredita (Fariña et al. 2013).

O Brasil reporta alguns casos de associações comportamentais entre o ser humano e a megafauna pleistocênica. Na Bahia, a predação humana por esses animais foi registrada em um úmero de Mylodonopsis ibseni por meio da observação de marcas de descarnamento (Prous 1992). No Mato Grosso, marcas antropogênicas foram identificadas em osteodermos de um Eremotherium laurillardi, provavelmente feitas com o objetivo de 
Primeiras abordagens sobre o Sítio Arqueológico-Paleontológico Araçá, Município de Corrente, Extremo Sul do Piauí R. Museu Arq. Etn., 30: 84-103, 2018.

confeccionar adornos (Neves \& Piló 2008).

Ainda no Brasil, e mais recentemente, dois casos merecem atenção: o primeiro foi registrado na Fazenda São José, município de Poço Redondo, Sergipe, pelo diagnóstico de modificações realizadas em um dente de Eremotherium laurillardi na construção de um adorno (Dantas 2012; Dantas et al. 2012). A referida amostra foi datada revelando uma idade entre 12.742 e $12.562 \mathrm{cal}$ AP $-10.740 \pm 3014 \mathrm{C} \mathrm{AP}$, UGAMS 14017, reforçando a hipótese de interação entre megafauna e ser humano no final do Pleistoceno na América do Sul (Dantas et al. 2014); o segundo caso refere-se a marcas de corte em elementos ósseos de um Hippidion principale, encontrados no abrigo Toca da Janela da Barra da Janela do Antonião, sudeste do Piauí, associados a ferramentas líticas e outros registros de natureza arqueológica (Bélo \& Oliveira 2013). Ademais, o sudeste do Piauí apresenta registros de espécimes pertencentes à megafauna em um período mais tardio, cerca de 6 mil anos.

No tocante às relações sincrônicas e espaciais, dois casos merecem destaque: 1 ) sítio arqueológico Monte Verde (centrosul do Chile), com evidências de ocupação humana há pelo menos 12,3 mil anos, além de fósseis de mastodontes associados a artefatos líticos, os quais, submetidos à datação, apresentaram uma idade estimada em 12 mil anos (Borrero 2009; Neves \& Piló 2008); 2) Lapa Vermelha IV, região de Lagoa Santa, Minas Gerais, Brasil, portadora do esqueleto humano mais antigo da América, com datação estimada entre 11,5 mil e 11 mil anos, e fósseis de megamamíferos com idades entre 9 mil e 10 mil anos (Neves \& Piló 2008).

As correlações espaciais são mais abundantes, sendo evidenciadas com maior facilidade. No sudeste do Piauí e no estado do Rio Grande do Norte, por exemplo, as ocorrências remontam, essencialmente, a fragmentos ósseos de representantes da megafauna do Pleistoceno final/Holoceno, dentre os quais o Eremotherium laurillardi (Megatheriidae) e instrumentos líticos em quartzito e sílex encontrados no mesmo depósito e/ou, inclusive, na mesma camada (Guérin et al. 2002; Santos Jr, Porpino \& Silva 2008).

No município de Corrente, tem-se o primeiro registro do esqueleto parcial de um
Eremotherium laurillardi, associado a um terraço fluvial com ocorrências de artefatos arqueológicos, especificamente, materiais líticos em arenito silicificado (Frazão 2015). Embora as evidências confirmem a presença de artefatos arqueológicos em um nível estratigráfico muito próximo ao dos fósseis da preguiça gigante, até o momento não foram encontradas marcas nas estruturas ósseas do Eremotherium que comprovem a presença de associações comportamentais entre a megafauna e o ser humano em algum momento do Pleistoceno final/Holoceno nesse sítio.

De maneira geral, as pesquisas que exploram essa temática ainda são incipientes, não sendo possivel estabelecer com clareza o papel da megafauna no cotidiano dos grupos humanos pré-coloniais que habitaram a América do Sul. Apesar disto, as datações obtidas em alguns desses contextos sugerem uma contemporaneidade entre o ser humano e os megamamíferos no Pleistoceno da América do Sul.

\section{Conclusões}

A presença de artefatos líticos no sítio tratado neste artigo, essencialmente confeccionados a partir do arenito silicificado, certamente está relacionada à presença de matéria-prima no ambiente. Sendo assim, todos os municípios do extremo sul do Piauí que apresentam características geoambientais semelhantes apresentam probabilidades de ocorrência desses recursos arqueológicos. Dessa maneira, essa particularidade deve ser considerada quando da realização de pesquisas arqueológicas futuras na região, assim como no cenário de construção de empreendimentos com potencial de causar impactos ambientais e patrimoniais.

Apesar dos poucos indícios da presença de outros espécimes de megamamíferos no município, estudos realizados no Parna Serra da Capivara, sudoeste do estado, têm revelado abundantes fósseis pleistocênicos em áreas com características sedimentológicas semelhantes ao contexto aqui abordado. Muitas vezes, os remanescentes ósseos são encontrados associados aos artefatos arqueológicos, 
no entanto, isso nem sempre denota contemporaneidade, pois pode ter ocorrido uma mistura espacial provocada, entre outros fatores, por processos erosivos. Nesse sentido, análises paleoambientais e geoarqueológicas são indispensáveis na compreensão dos processos naturais e antrópicos envolvidos na criação dos registros arqueológico e paleontológico.

A partir das análises, percebeu-se que as características peculiares do sítio e seu entorno permitem a formulação de vários questionamentos, estes essenciais para a compreensão do paleoambiente local. Até então, as investigações indicam que a presença de artefatos arqueológicos na Área 1 está conectada à disponibilidade de matériaprima, particularmente à ocorrência de abundantes arenitos silicificados dispersos em um paleoleito do atual Rio Grande. No que se refere à relação entre ser humano e a megafauna, até o momento as evidências sugerem apenas associação espacial.

Inserido no contexto da região em foco, este trabalho poderá não apenas subsidiar pesquisas arqueológicas no contexto da arqueologia de salvamento, mas também auxiliar os órgãos competentes no sentido de avaliar o patrimônio arqueológico do extremo sul piauiense. A realização de testes nos demais municípios do extremo sul do estado poderá fornecer informações relevantes para a elaboração de um modelo preditivo, considerando a relação entre disponibilidade de matériaprima e presença de materiais arqueológicos líticos.

No Brasil, os trabalhos desenvolvidos nesse viés foram escassos durante as décadas de 1990 e em parte dos anos 2000, e apesar da ampliação recente no número de trabalhos com essa perspectiva (Aires da Fonseca, 2013, 2016, 2018; Perez, Afonso \& Mota, 2018), houve durante muito tempo a ideia de que, apesar dos avanços teóricos e metodológicos, a maioria dos projetos arqueológicos não considerassem os aspectos que norteiam a concepção de modelos (Kipnis 1997).

A continuidade dos estudos (Oliveira 2017; Frazão 2018) têm auxiliado no preenchimento das lacunas existentes, especialmente, no tocante à sequência estratigráfica do sítio, ao contexto paleodeposicional, as características tecnológicas dos materiais líticos, e quanto as possíveis relações entre a megafauna e o ser humano no sítio Araçá.

FRAZÃO, K.M.R.; CISNEROS, J.C.; SILVA, A.S.N.F. First approaches to the Araçá archaeological-palaeontological site, municipality of Corrente, southernmost Piauí. R. Museu Arq. Etn., 30: 84-103, 2018.

\begin{abstract}
This article aims to provide preliminary analyses and suggest the construction of a predictive model for archaeology in southernmost Piauí State, taking into account the geoenvironmental features of the region and a paleontological and archaeological site in the municipality of Corrente, Piauí. The study area features silicified sandstone and conspicuous lithic artifacts, mostly produced from this raw material, in addition to fossil remains of Eremotherium laurillardi, a mammal species typical from the American end-Pleistocene. It is thought that the presence of lithic instruments is linked to the availability of the prime matter, thus, a predictive model considering this pattern predicts the probability of archaeological resources in other areas that expose sedimentary layers bearing silicified sandstone. Although the presence of lithic artifacts in the fossil area has been observed, detailed stratigraphic and paleoenvironmental analyzes of the outcrop as well as dating of the evidence will be necessary to better understand the relationship between humans and megafauna at this site.
\end{abstract}

Keywords: Geology; Lithic tools; Megafauna; Pleistocene-Holocene transition; Regional sampling. 
Primeiras abordagens sobre o Sítio Arqueológico-Paleontológico Araçá, Município de Corrente, Extremo Sul do Piauí R. Museu Arq. Etn., 30: 84-103, 2018.

\section{Referências bibliográficas}

Aguiar, R.B.; Gomes, J.R.C. (Orgs.). 2004a. Projeto cadastro de fontes de abastecimento por água subterrânea, estado do Piauí: diagnóstico do município de Avelino Lopes. CPRM, Fortaleza.

Aguiar, R.B.; Gomes, J.R.C. (Orgs.). 2004b. Projeto cadastro de fontes de abastecimento por água subterrânea, estado do Piauí: diagnóstico do município de Corrente. CPRM, Fortaleza.

Aguiar, R.B.; Gomes, J.R.C. (Orgs.). 2004c. Projeto cadastro de fontes de abastecimento por água subterrânea, estado do Piauí: diagnóstico do município de Cristalândia do Piauí. CPRM, Fortaleza.

Aguiar, R.B.; Gomes, J.R.C. (Orgs.). 2004d. Projeto cadastro de fontes de abastecimento por água subterrânea, estado do Piauí: diagnóstico do município de Curimatá. CPRM, Fortaleza.

Aguiar, R.B.; Gomes, J.R.C. (Orgs.). 2004e. Projeto cadastro de fontes de abastecimento por água subterrânea, estado do Piauí: diagnóstico do município de Júlio Borges. CPRM, Fortaleza.

Aguiar, R.B.; Gomes, J.R.C. (Orgs.). 2004f. Projeto cadastro de fontes de abastecimento por água subterrânea, estado do Piauí: diagnóstico do município de Morro Cabeça no Tempo. CPRM, Fortaleza.

Aguiar, R.B.; Gomes, J.R.C. (Orgs.). 2004g. Projeto cadastro de fontes de abastecimento por água subterrânea, estado do Piauí: diagnóstico do município de Parnaguá. CPRM, Fortaleza.

Aguiar, R.B.; Gomes, J.R.C. (Orgs.). 2004h. Projeto cadastro de fontes de abastecimento por água subterrânea, estado do Piauí: diagnóstico do município de Riacho Frio. CPRM, Fortaleza.

Aguiar, R.B.; Gomes, J.R.C. (Orgs.). 2004i. Projeto cadastro de fontes de abastecimento por água subterrânea, estado do Piauí: diagnóstico do município de Sebastião Barros. CPRM, Fortaleza.
Aires da Fonseca, J. 2013. Levantamento regional na arqueologia amazônica: o uso de sistema de informação geográfica e sensoriamento remoto. Boletim do Museu Paraense Emílio Goeldi: Ciências Humanas 8: 675-690.

Aires da Fonseca, J. 2016. Aspectos teóricos e metodológicos no uso de modelos arqueológicos preditivos: uma abordagem na Amazônia brasileira. In: Magalhães, M.P. (Org.). Amazônia antropogênica. Museu Paraense Emílio Goeldi, Belém, 177198.

Aires da Fonseca, J. 2018. Padrões de distribuição espacial e modelos preditivos: os sítios arqueológicos no baixo curso dos rios Nhamundá e Trombetas. Boletim do Museu Paraense Emílio Goeldi: Ciências Humanas 13: 353376.

Andrade Jr., A.S.A. et al. 2004a. Atlas climatológico do estado do Piauí. Embrapa MeioNorte, Teresina.

Andrade Jr., A.S.A. et al. 2004b. Classificação climática do estado do Piauí. Embrapa MeioNorte, Teresina.

Araujo, A.G.M. 1992. As propriedades físicas dos arenitos silicificados e suas implicações na aptidão ao lascamento. Revista do Museu de Arqueologia e Etnologia 2: 63-74.

Araujo, A.G.M. 1999. As geociências e suas implicações em teoria e métodos arqueológicos. Revista do Museu de Arqueologia e Etnologia 3: 3545 .

Araujo, A.G.M. 2001. Teoria e método em arqueologia regional: um estudo de caso no Alto Paranapanema, estado de São Paulo. Tese de doutorado. Universidade de São Paulo, São Paulo.

Bélo, P.S.; Oliveira, É.V. 2013. Análise tafonômica de marcas em restos esqueletais de Hippidion, sítio Toca da Janela da Barra do Antonião, Piauí, Brasil. Estudos geológicos 23: 5979. 
Binford, L.R. 1972. The new archaeology: an American archaeologist gives his own opinion. The Listener 87: 174176.

Binford, L. 2001. Where do research problems come from? American Antiquity 66: 669678.

Bitencourt, A.L.V. 2008. Princípios, métodos e algumas aplicações da geoarqueologia. In: Rubin, J.C.R.; Silva, R.T. (Orgs.). Geoarqueologia: teoria e prática. Pontifícia Universidade Católica de Goiás, Goiânia, 4170

Borrero, L.A. 2009. The elusive evidence: the archaeological record of the South American extinct megafauna. In: Haynes, G. (Ed.). American megafaunal extinctions at the end of the Pleistocene. Springer, New York, 145168.

Campos, J.E.G.; Dardenne, M.A. 1997. Origem e evolução tectônica da Bacia Sanfranciscana. Revista Brasileira de Geociências 27: 283294.

Castro, A.A.J.F. 2007. Unidades de Planejamento: uma proposta para o estado do Piauí com base na dimensão diversidade de ecossistemas. Publicações Avulsas em Conservação de Ecossistemas 18: 128.

CPRM - Companhia de Pesquisa de Recursos Minerais. 2006. Mapa geológico do estado do Piauí. Secretaria de Geologia, Mineração e Transformação Mineral, Teresina.

Crawford, O.S.G. 1912. The distribution of early Bronze Age settlements in Britain. Geographical Journal 40: 184203.

Crawford, O.S.G. 1922. Prehistoric geography. Geographical Review 12: 257263.

Criado Boado, F. 1999. Capa 6: criterios y convenciones en arqueología del paisaje: del terreno al espacio: planteamientos y perspectivas para la arqueología del paisaje. Grupo de Investigación en Arqueología del Paisaje, Santiago de Compostela.

Dantas, M.A.T. 2012. Contribuição ao conhecimento da megafauna pleistocênica da Região Intertropical brasileira. Tese de doutorado. Universidade Federal de Minas Gerais, Belo Horizonte.

Dantas, M.A.T. et al. 2012. An anthropogenic modification in an Eremotherium tooth from northeastern Brazil. Quaternary International 253: 107109.

Dantas, M.A.T. et al. 2014. Dated evidence of the interaction between humans and megafauna in the late Pleistocene of Sergipe state, northeastern Brazil. Quaternary International 352: 197199.

Fariña, R.A. et al. 2013. Arroyo del Vizcaíno, Uruguay: a fossilrich 30kaold megafaunal locality with cutmarked bones. Proceedings of the Royal Society B 281: 16.

Felice, G.D. 2006. Contribuição para estudos geoarqueológicos e paleoambientais: proposta metodológica (estudo de caso: Maciço Calcário do Garrincho, Piauí, Brasil). Tese de doutorado. Universidade Federal de Pernambuco, Recife.

Ferreira, R.V.; Dantas, M.E. 2010. Relevo. In: Pfaltzgraff, P.A.S.; Torres, F.S.M.; Brandão, R.L. (Orgs.). Geodiversidade do estado do Piauí. CPRM, Recife, 4764.

Fogaça, E.; Lourdeau, A. 2008. Uma abordagem tecnofuncional e evolutiva dos instrumentos planoconvexos (lesmas) da transição Pleistoceno/Holoceno no Brasil central. Revista FUMDHAMentos 7: 261347.

Fonseca Jr., J.A.A. 2013. Levantamento regional na arqueologia amazônica: o uso de sistema de informação geográfica e sensoriamento remoto. Boletim do Museu Paraense Emílio Goeldi: Ciências Humanas 8: 675690.

Frazão, K.M.R. 2015. Estudo preliminar de um sítio arqueológico e paleontológico, município de Corrente, extremo sul do Piauí, e proposta de um modelo preditivo. Trabalho de conclusão de curso. Universidade Federal do Piauí, Teresina.

Frazão, K.M.R. 2018. Sítio Arqueológico-Paleontológico Araçá, município de Corrente (PI): contexto 
Primeiras abordagens sobre o Sítio Arqueológico-Paleontológico Araçá, Município de Corrente, Extremo Sul do Piauí R. Museu Arq. Etn., 30: 84-103, 2018.

geoarqueológico e paleodeposicional. Dissertação de mestrado. Museu Nacional da Universidade Federal do Rio de Janeiro, Rio de Janeiro.

Funari, P.P.A. 1988. Arqueologia. Ática, São Paulo.

Gamble, C. 2008. Archaeology: the basics. 2. ed. Routledge, New York.

Greene, K. 2003. Archaeology: an introduction. Taylor \& Francis, London.

Guérin, C. et al. 2002. Toca da Janela da Barra do Antonião, São Raimundo Nonato, Piauí: rica fauna pleistocênica e registro da préhistória brasileira. Sigep 69: 131137.

Guidon, M.S. et al. 2003. A revised chronology of the lowest occupation layer of Pedra Furada Rock Shelter, Piauí, Brazil: the Pleistocene peopling of the Americas. Quaternary Science Reviews 22: 2303-2310.

IBGE - Instituto Brasileiro de Geografia e Estatística. 2002. Mapa de clima do Brasil. Ministério do Planejamento, Orçamento e Gestão, Rio de Janeiro.

Jacomine, P.K.T. et al. 1986. Levantamento exploratório: reconhecimento de solos do estado do Piauí. Embrapa, Rio de Janeiro.

Jochim, M.A. 1976. Hunter-gatherer subsistence and settlement: a predictive model. Academic Press, New York.

Kipnis, R. 1997. Uso de modelos preditivos para diagnosticar recursos arqueológicos em áreas a serem afetadas por empreendimentos de impacto ambiental. In: Caldarelli, S.B. (Org.). Atas do Simpósio sobre Política Nacional do Meio Ambiente e Patrimônio Cultura, Fórum Interdisciplinar para o Avanço da Arqueologia. IGPAUCG, Goiânia, 3440.

Kohler, T.A. 1988. Predictive locational modelling: history and current practice. In: Judge, W.; Sebastian, L. (Eds.). Quantifying the present and predicting the past. Government Printing Office, Washington, 1960.
Lima, E.A.M.; Brandão, R.L. 2010. Geologia. In: Pfaltzgraff, P.A.S.; Torres, F.S.M.; Brandão, R.L. (Org.). Geodiversidade do estado do Piauí. CPRM, Recife, 1724.

Lima, I.M.M.F. 1987. Relevo piauiense: uma proposta de classificação. Carta Cepro 12: 5584.

Lourdeau, A. 2006. A pertinência de uma abordagem tecnológica para o estudo do povoamento préhistórico do Planalto Central do Brasil. Habitus 4: 685710.

Mabessone, J.M. 2002. História geológica da província Borborema (NE Brasil). Revista de Geologia 15: 119129

Marques, M.; Hilbert, K. 2009. A tradição (arqueológica) itaparica: a materialidade textual e a semantização dos objetos. Revista Trajetos 7: 6880 .

MMA - Ministério do Meio Ambiente. 2006. Caderno da região hidrográfica do Parnaíba. MMA, Brasília.

Morais, J.L. 1999. Perspectivas geoambientais da arqueologia do Paranapanema paulista. Tese de doutorado. Universidade de São Paulo, São Paulo.

Neves, W.A; Piló, L.B. 2008. O povo de Luzia: em busca dos primeiros americanos. Globo Editora, São Paulo.

Oliveira L.S. 2017. Um ateliê no extremo sul piauiense: uma abordagem inclusiva da produção lítica no município de Corrente, Piauí. Dissertação de mestrado. Universidade Federal do Piauí, Teresina.

Perez, G.C; Afonso, M.C.; Mota, L.T. 2018. Métodos de análise espacial para sítios arqueológicos: um modelo preditivo para o estado de São Paulo. Cadernos do Lepaarq 15: 98-120.

Periman, R.D. 2005. Modeling landscapes and past vegetation patterns of New Mexico's Rio del Oso Valley. Geoarchaeology 20: 193210. 
Pilgram, T. 1987. Predicting Archaeological Sites from Environmental Variables. BAR publishing, Oxford.

Plog, S.; Hegmon, M. 1993. The samplerichness relation: the relevance of research questions, sampling strategies, and behavioral variation. American Antiquity 58: 489496.

Prous, A. 1992. Arqueologia brasileira. UnB, Brasília.

Prous, A. 1997. O povoamento da América visto do Brasil: uma perspectiva crítica. Revista USP 34: 821 .

Prous, A.; Ribeiro, L. 2010. As pesquisas de arte rupestre no Brasil. In: Anais do $14^{\circ}$ Congresso Internacional da Ifrao, 2010, Piauí.

Rapp, G.R.; Hill, C.L. 2006. Geoarchaeology: the Earthscience approach to archaeological interpretation. 2. ed. Yale University Press, New Haven.

Redman, C.L. 1973. Multistage fieldwork and analytical techniques. American Antiquity 38: 6179 .

Santos, M.E.C.M.; Carvalho, M.S.S. 2004. Paleontologia das bacias do Parnaíba, Grajaú e São Luís: reconstituições paleobiológicas. 2. ed. CPRM, Rio de Janeiro.

Santos Jr., V.; Porpino, K.O.; Silva, A.S.N.F. 2008. A megafauna extinta e os artefatos culturais de um tanque natural na região central do Rio Grande do Norte. Contexto 3: 176193.
Schmitz, P.I. 1980. A evolução da cultura no sudoeste de Goiás, Brasil. Pesquisas: série Antropologia 31: 185225.

Schmitz, P.I.; Novasco, R.V. 2011. Arqueologia no planalto: o uso do SIG na aplicação de análises espaciais dos sítios arqueológicos da localidade Boa Parada, Município de São José do Cerrito, SC. Museu de Arqueologia e Etnologia 21: 167183.

Silva, J.C. 2003. Arqueologia no médio São Francisco: indígenas, vaqueiros e missionários. Tese de Doutorado. Universidade Federal de Pernambuco, Recife.

Trigger, B.G. 2004. História do pensamento arqueológico. São Paulo: Odysseus.

Tsuchiya, Í. et al. 2002a. Utilização de regressão logística para avaliação de prováveis áreas de ocupações pretéritas. In: Anais do $2^{\circ}$ Simpósio Brasileiro de Geomática, 2002, São Paulo, 565573.

Tsuchiya, Í. et al. 2002b. Visualização cartográfica como ferramenta de suporte à implementação de um modelo preditivo em arqueologia: um estudo de caso. In: Anais do $2^{\circ}$ Simpósio Brasileiro de Geomática, 2002, São Paulo, 574584.

Warren, R.E. 1990. Predictive modelling in archaeology: a primer. In: Allen, K.M.S.; Green, S.W.; Zubrow, E.B.W. (Eds.). Interpreting space: GIS and archaeology. Taylor \& Francis, London, 90111.

White, T.D.; Folkens, P.A. 2005. The human bone manual. Elsevier Academic Press, San Diego. 